\title{
SMOKING AND SCHOOLING
}

\author{
In Search of the Missing Link \\ Kenneth E. WARNER \\ Sihool of Public Health, University of Michigan, Ann Arbor, MI 48109, USA \\ Received August 1982
}

Cigarette smoking is the number one source of preventable morbidity and premature mortality in the United States. An extensive body of epidemiological research has firmly established this fact [U.S. Department of Health, Education, and Welfare (1979b)] and the results of the research have been communicated frequently to the public over the past three decades. ${ }^{1}$

There is considerable evidence that the information-dissemination effort has had significant impacts on the nation's smoking behaviors. The Surgeon General has estimated that over 30 million Americans have quit smoking since 1964 [U.S. Department of Health, Education, and Welfare (1979b)]. The percentages of both adults and teenagers who smoke have fallen, fo: both sexes [U.S. Department of Health and Human Services (1980)]. National per capita cigarette consumption, an often-watched index of the nation's smoking habit, has dropped annually over the past decade, a period when a variety of factors might otherwise have been expected to increase this index substantially [Warner (1981)]. And the rapidity of the shift toward lower tar and nicotine cigarettes has been nothing short of phenomenal: in the period 1971-1974, only 7.5 percent of cigarettes were classified as low tar and nicotine (defined as $15 \mathrm{mg}$ 'tar' or less); the figure reached nearly 50 percent in 1980, and then leaped to 65 percent in 1981 [U.S. Department of Agriculture (1981)].

Despite these apparently encouraging trends, the magnitude of the remaining smoking-and-health problem is awesome. Over 50 million

\footnotetext{
${ }^{1}$ The vehicles for translating research findings irto language readily accessible to the average citizen have included articles on smoking and health in popular magazines [for example, in Reader's Digest and Consumer Reports in the 1950s; see Lieb (1953), Miller and Monahan (1954), and Norr (1952)]; anti-smoking 'commercials' on television end radio [Warner (1979)]; media publicity following the release of each of a series of Surgeon General's reports on smoking and health [e.g. U.S. Department of Health, Education, and Weli'tre $(1964,1979 \mathrm{~b})$, and U.S. Department of Health and Human Services $(1980,1981,1982)]$; and health education in the nation's schools and other community organizations [U.S. Depariment of Health, Education, and Welfare (1979a)].
} 
Americans continue to smoke, and the average daily cigarette consumption of these smokers has risen [Harris (1979)]. Cigarette smoking annually claims ciose to 350,000 lives and accounts for more than 80 million excess days of work loss and over 145 million excess days of bed disability [U.S. Department of Health, Education, and Welfare (1979b)]. Some smokingrelated disease problems are growing steadily worse. ${ }^{2}$

With evidence such as this, we can conclude that the smoking-and-health information dissemination effort has been a partial success, with emphasis placed on the modifier. What accounts for the positive response to the smoking-and-health message, and what accounts for the limited degree of that response? More fundamental is the underlying question: what are the determinants of individuals' decisions to smoke cigarettes?

Social scientists have tackled these questions in hundreds of studies, and a substantial body of knowledge has emerged. We know, for example, that peer pressure affects smoking, and that the children of smokers are more likely to smoke than are the children of non-smokers. A larger percentage of blacks smoke than of whites. Blue-collar workers are more likely to smoke than are white-collar workers, and people currently unemployed have the highest smoking rate of any occupational category. People who are separated or divorced smoke in greater percentages than those who are married. Beyond the level of grade school, srnoking is inversely correlated with years of schooling. And so on [U.S. Department of Heaith. Education, and Welfare (1979b)].

This information is undoubtedly important. Nevertheless, much of it must be characterized as fragmentary and, in many instances, superficial. It begs the basic question of why, of causality, and thereby it affords limited insight into the behavioral question of how smokers, and potential smokers, might be encouraged to reduce their risks of experiencing smoking-related illness. Of course, the task of resolving causality issues is immensely difficult, given the complex web oi psycho-social factors, the numerous and varied pro- and anti-smoking stimuli, and the multi-faceted character of both smoking behaviors and responses to anti-smoking cues.

Before the normative-science questions can be addressed - for example, how can we encourage fewer young people to initiate smoking habits - a number of positive-science questions must be examined much more closely than they have been to date. The article by Farrell and Fuchs in this issue of the Journal represents an attempt to undertake such an examination with regard to the relationship between schooling and cigarette smoking. Does the negative correlation reflect causation - does an increase in the quantity of

\footnotetext{
${ }^{2}$ Most alarming is the epidemic of lung cancer among women. The rapid growth rate of that disease, associated with the spread of smoking among women since World War II, is causing lung cancer to surpass breast cancer as the leading cause of cancer mortality in women [U.S. Department of Health and Human Services (1980)].
} 
schooling somehow 'train' or assist the student to decide not to smoke - or does the correlation result from the influence of one or more third variables on both schooling and smoking?

Of all the associations between smoking and other attributes, the relationship between smoking and schooling is of particular interest to the community of social scientists concerned with issues of smoking and health. Historically, Americans (and certainly American academics) have exhibited a great enthusiasm for education as an egalitarian and effective vehicle for fostering indivioual betterment and producing desirable social change. In recent years, the formal educational system has been relied upon increasingly to transmit a knowledge of 'proper' personal and social behaviors, in addition to the traditional 'three R's' (reading, writing, arithmetic). This has been particularly true in the area of health behavior, where instruction related to sexuality and the use of alcohol, tobacco, and other drugs has become relatively commonplace [U.S. Department of Health, Education, and Welfare (1979a)].

Within the community of smoking-and-health scholars, education is viewed as the sine qua non of the effort to move the nation toward a population of non-smokers. Media publicity accorded smoking-and-iteaith research findings is considered a userul form of 'mass education', but the hallmark of the smoking-and-health education effort is the attempt to get effective health education programs into the nation's elementary and secondary school classrooms. Virtually all states require instruction related to smoking in their public schools, though the requirement is often poorly defined and unenforced. And health education researchers are working vigorously to refine the techniques of instruction in order to make the effort more effective. ${ }^{3}$

With this as background, it can be easily understood why the schoolingsmoking correlation has long been viewed with interest. Yet prior to the analysis reported by Farrell and Fuchs, the issue of causation has received little scholarly attention. Resolution of the causation issue would represent an important necessary (though not sufficient) positive-science contribution to the normative-science question of how the nation's smoking habit can be made less hazardous. In this context, Farrell and Fuchs' analysis is a welcome first step toward understanding the smoking and education link.

In considering the contribution of Farrell and Fuchs' work, however, it is

\footnotetext{
${ }^{3}$ The sophistication of health education research has grown considerably beyond the debate over what facts of smoking and health should be presented and in what format. Ongoing research is exploring techniques, including the use of peer counseling and role playing, to teach coping skills so that children and teenagers can withstand the social pressures to engage in selfdestructive behaviors, such as smoking. The development of coping skills is viewed as an integral component of behavior-specific health education (e.g., on tobacco use), but it is also seen as a necessary generic component of all health education. For a discussion of specific innovative smoking-and-health school curricula, see Green (1979).
} 
a bit unfair to thrust the authors into the thick of the health educators' debate. That emphasis in this essay reflects the principal interest in their article of an economist whose central concern is the substantive issues of smoking and health. Certainly Farrell and Fuchs' objective was not to address the normative-science questions which lie at the heart of health education. Furthermore, the intellectual motivation of the authors derives not from an immediate concern with smoking and health. Rather, as they clearly articulate it, they are interested in probing further the relationship between schooling and health status in order to explore a hypothesis suggested by Grossman (1975), namely that additional years of schooling make an individual a more efficient producer of his or her own health. Thus, it is possible to interpret Farrell and Fuchs' work in two contexts, one being the analytical contribution that they make to the human capital research tradition in health economics (their choice), the other being their substantive contribution to understanding of the determinants of smoking behavior.

Regarding the former, Grossman (1975) has explained the correlation between additional years of schooling and health status in a causal, human capital investment fashion. As Farrell and Fuchs characterize this argument: 'Schooling could increase knowledge about health effects of behavior and medical care options, change preferences, or train a person to better process and act upon information. Or [with credit accorded Thaler and Shefrin (1981)] perhaps schooling increases the individual's ability to develop strategies of self-control.' The alternative is an indirect, third-variable explanation. That is, increased schooling may not produce greater health status; rather, underlying individual differences, such as family socialization, mental ability, or internal rate of time preference, might affect both schooling and health behaviors, thereby resulting in a non-causal correlation between the two.

This is the issue that Farrell and Fuchs address by studying survey data exhibiting the conventional link between years of schooling and smoking. The authors determine that ' $[t]$ he relative differences in the probability of smoking that are observed at age 24 between persons with differing years of schooling are already present at age 17, before the schooling is obtained'. Hence, they conclude that ' $[t]$ he additional schooling cannot be the cause of the differential smoking behavior, since the realization of the schooling does not have any marginal effect on the size of the schooling coefficient [in maximum likelihood logit regressions]'. The authors also observe that health concerns appear to have motivated, at least partially, differences in smoking by years of schooling. This conclusion derives from the finding that the regression schooling coefficients are non-significant for the cohorts of survey respondents who matured prior to public discussion of the health effects of smoking (beginning in 1953), while the coefficients are strongly and significantly negative for the later cohorts. 
Farrell and Fuchs briefly consider some alternative, third-variable explanations for the schooling-smoking correlation. They reject differences in 'social class', lean against differences in individual mental ability, and offer individual variations in time discount as a plausible explanation. Nevertheless, the bottom line of the analysis is an essentially negative finding: the data cannot support the proposition that years of schooling produce non-smoking, and by extension that years of schooling produce better health. The important third variable remains a mystery.

The Farrell-Fuchs conclusion is both enlightening and troublesome; at minimum, and much to the authors' credit, it is thought-provoking. As suggested above, there is an abundance of evidence that education, in the broadest sense of the word, has had a significant impact on smoking behavior. The authors' finding regarding the impact of public discussion of the health effects of smoking on the schooling coefficients lends further support to this conclusion. Educationally distinct groups reacted distinctly differently to health information bruught into the public domain, but according to Farrell and Fuchs, their years of education, social class, and basic mental aptitudes cannot explain their differences in absorbing, processing, and using the information.

The easiest explanation for the mystery is that years of schooling is not a good measure of quantity of education, and furthermore that quantity and quality of education are not synonymous. Farrell and Fuchs consider this possibility and reject it as implausible. They observe that '[d]ifferences in quality ... are similar to additional years of schooling because both reflect differences in the quantity of education inputs into the individual'. Furthermore, they do not understand how schooling could increase knowledge, change preferences, increase ability for self-control, or otherwise exert strong influence over smoking behavior until the 12th grade and not thereafter'.

While it is difficult to counter this logic, one is left with a set of circumstances which might respond adequately to it: most smoking-initiation decisions are reached while individuals are in their teens; hence it is precollege education that is relevant to most smoking-initiation decisions, and the marginal effect of college years would thus be expected to be very small; finally, higher quality secondary education is associated with a greater probability of post-secondary schooling. Farrell and Fuchs' analysis makes it more difficult to conclude that 'schooling produces non-smoking', but it does not eliminate all of the logical possibilities.

I am more reluctant to accept the authors' dismissal of differences in mental ability as a third-variable explanation. Their rejection of this explanation is based on the expectation that the schooling-smoking correlation would have become weaker over time 'as knowledge about the harmful effects of smoking became more widely diffused', a weakening the 
authors did not find in their cohort analysis. This logic ignores the significantly varying rates of information flow into the public domain at different times, changes in the nature of the information, and the surprisingly large pockets of ignorance about basic smoking-and-health facts even in the late 1970s [Myers, Iscoe and Jennings et al. (1981)]. Furthermore, the authors can compare only two birth cohorts for this purpose (1953-63 and 1964-72), and the results of a sex-differentiated comparison are not unsupportive of the mental abilities hypothesis: for the males, the magnitude of the schooling coefficient diminishes from the first to the second cohort; even if the difference is not statistically significant, the direction of the change is consistent with the mental abilities hypothesis. For the females, one might expect the schooling factor to grow in importance over time, since virtually all of the early evidence linking smoking to illness concentrated exclusively on men. Indeed, the first Surgeon General's report to focus on smoking and illness in women was published in 1980 [U.S. Department of Health and Human Services (1980)]. Again, the cohort data are not inconsistent with the mental abilities explanation. I think this explanation deserves more careful consideration than the authors' data permit.

Regardless of one's acceptance of the strength of Farrell and Fuchs' conclusions, one must credit the authors with having made an important and provocative analytical contribution in an area in which assumption and assertion have dominated. In terms of the human capital research tradition in health economics, this work clearly challenges what has become the conventional wisdom for some scholars that schooling per se produces health. If that assessment is to retain - or indeed now earn - its status as conventional wisdom, work such as this will force proponents to define 'schooling' in a more detailed and meaningful operational manner and to seek out much more refined data on educational experience.

The fields of health education and other social science research on smoking and health are also informed by Farrell and Fuchs' study, though the utility of the analysis seems smaller in this area. The work of Farrell and Fuchs may jar some health educators out of a complacency that regards as an article of faith the notion that education produces desirable health behaviors. Nevertheless, the prescriptively-oriented health educator will be less content with this essentially negative finding than will the human capital theorist. And more importantly, the operational issue regarding smoking and education is not addressed by the Farrell-Fuchs analysis: increasing years of schooling is not a viable (nor a sensible) alternative for the sole purpose of achieving a smoking-and-health literate population. Rather, the task confronting health educators is how to design and implement specific instructional curricula to achieve the desired understanding. This is a field that is in its intellectual infancy (perhaps adolescence). Of the cohorts studied by Farrell and Fuchs, only the very youngest (1964-72) might have been 
exposed to specific smoking-and-health instruction, and that instruction would have been very limited in quantity and primitive by today's standards [Green (1979)]. Farrell and Fuchs' analysis should not discourage continued efforts to develop specific health education curricula. By contrast, however, it should encourage much more careful evaluation of the effectiveness of such curricula than has been the norm in the past.

A good, thought-provoking study invariably leaves a reader with ideas of related issues which might benefit from a similar type of analytical scrutiny. I will close this essay with three such issues that I would place on my future smoking-and-schooling-research wish list.

First, and most directly, does the authors' principal finding hold for a broader range of levels of educational attainment, and in particular for lower levels? While one can sympathize with Farrell and Fuchs' reasons for restricting their sample to survey respondents with 12 to 18 years of schooling, one wonders whether causality could be rejected when comparing, say, ninth grade educations with twelfth grade educations. Again, the early ages at which most smoking-initiation decisions are reached makes such a comparison seem important.

Second, what (if any) is the link between smoking cessation and schooling? By examining smoking behavior only to age 24, Farrell and Fuchs could not investigate this important question. Of course, even had they looked beyond age 24, the authors could not have employed the same methodology to address the causality issue, since smoking cessation generally occurs beyond the age at which schooling has been completed. Nevertheless, with over 30 million Americans having quit in the past two decades - many, if not most, presumably as a result of their smoking-and-health educations - the question seems an important one. Could the skills or knowledge that, for example, a Grossman might attribute to schooling be more relevant to the desire and ability to quit smoking than not to start?

Third, and similarly, what if any are the links between schooling and smoking behaviors other than the simple question of smoking status? The most profound change in smoking in the past decade has been the shift toward lower tar and nicotine $(t / n)$ cigarettes. Much of this shift must reflect 'health scare' - response to the adverse information on smoking and health and to the purported risk reduction. of low $t / n$ smoking. Does schooling predispose people in certain education categories to adopt low $t / n$ brands of cigarettes in greater percentages? This question is amenable to the kind of analysis Farrell and Fuchs direct toward the issue of basic smoking status.

\section{References}

Green, Dorothy, 1979, Ycuth education, in: U.S. Department of Health, Education, and Welfare, Public Health Service, Smoking and health: A report of the Surgeon General (Gove.nment Printing Office, Washington, DC) ch. 20. 
Grossman, Michael, 1975, The correlation between health and schooling, in: Nestor Terleckyj, ed., Household production and consumption (Columbia University Press, New York) 147223.

Harris, Jeffrey, 1979, Appendix: Cigarette smoking in the United States, 1950-1978, in: U.S. Department of Health, Education, and Welfare, Public Health Service, Smoking and health: A report of the Surgeon General (Government Printing Office, Washington, DC) app.

Lieb, C., 1953, Can the poisons in cigarettes be avoided?, Reader's Digest 63, 45-47.

Miller, L. and J. Monahan, 1954, The facts behind the cigarette controversy, Reader's Digest 65, 1-6.

Myers, Matthew, Craig Iscoe, Carol Jennings et al, 1981, Staff report on the cigarette advertising investigation (Federal Trade Commission, Washington, DC).

Norr, R., 1952, Cancer by the carton, Reader's Digest 61, 7-8.

Thaler, Richard and H. Shefrin, 1981, An economic theory of self control, Journal of Political Economy 89, 392-406.

U.S. Department of Agriculture, Economic Research Service, 1981, Tobacco outlook \& situation, TS-178, Dec. (Government Printing Office, Washington, DC).

U.S. Department of Health and Human Services, Public Health Service, 1980, The health consequences of smoking for women: A report of the Surgeon General (Government Printing Office, Washington, DC).

U.S. Department of Heaith and Human Services, Public Health Service, 1981, The health consequences of smoking - The changing cigarette: A report of the Surgeon General (Government Printing Office, Washington, DC).

U.S. Department of Health and Human Services, Public Health Service, 1982, The health consequences of smoking - Cancer: A report of the Surgeon General (Government Printing Office, Washington, DC).

U.S. Department of Health, Education, and Welfare, Public Health Service, 1964, Smoking and health: Report of the advisory committee to the Surgeon General of the United States (Government Printing Ofice, Washington, DC).

U.S. Department of Health, Education, and Welfare, Public Health Service, 1979a, School health in America, 2nd ed. (Government Printing Office, Washington, DC).

U.S. Department of Health, Education, and Welfare, Public Health Service, 1979b, Smoking and health: A report of the Surgeon General (Government Printing Office, Washington, DC).

Warner, Kenneth, 1979, Clearing the airwaves: The cigarette ad ban revisited, Policy Analysis 5 , 435-450.

Warner, Kenneth, 1981, Cigarette smoking in the 1970's: The impact of the anti-smoking campaign on consumption, Science 211, 729-731. 